\title{
An Analysis on the Economic Effect of Local Government Size Based on the data of Gansu, Qinghai, Ningxia and Xinjiang
}

\author{
Yang Liqin, Liu Haibin, Zhang Xuna \\ School of Economics and Management, Lanzhou Jiaotong University, Lanzhou,730070
}

\begin{abstract}
This paper uses the data on four provinces in Northwest China from 2000 to 2015 to establish a panel model to test the long-term relationship between the size of provincial governments and economic growth, industrialization, urbanization and marketization, and estimates the results by using the fixed effect model, and obtains the empirical results of the size of the four provinces in Northwest China for the above four effects.
\end{abstract}

\section{Introduction}

In recent years, the size and economy of China's local governments have witnessed rapid growth (Fan Ziying, Zhang Jun, 2010). However, there is a large gap in China's economic development level, and there is a large difference in the size of the government. What will be the effect of local government size on local economy? Many scholars study the effect of government size on economy from the perspective of the relationship between government size and economic growth. The larger the size of the government, the more resources it has, the stronger its ability of administrative intervention, and its effect on the economy is also multifaceted. Urbanization, industrialization and marketization are the main "hands" for local governments to develop economy, and are the targets of government macro-control. In the past, there were few studies on the influence of government size on urbanization.

\section{Empirical model, Variables and Data Description}

\section{1 empirical model}

This paper uses the data of four provinces in Northwest China from 2000 to 2015 to test the economic effect of government size, which is measured by the ratio of fiscal expenditure to GDP.

$$
\begin{array}{r}
\operatorname{lny}_{\mathrm{it}}=\beta_{0}+\beta_{1} \mathrm{Sca}_{\mathrm{it}}+\delta_{i} X_{\mathrm{it}}+\mu_{\mathrm{i}}+\mathrm{v}_{\mathrm{t}}+\varepsilon_{\mathrm{it}} \\
\operatorname{ind}_{i t}=\beta_{0}+\beta_{1} \mathrm{Sca}_{\mathrm{it}}+\delta_{i} X_{\mathrm{it}}+\mu_{\mathrm{i}}+\mathrm{v}_{\mathrm{t}}+\varepsilon_{\mathrm{it}}(2)
\end{array}
$$

$$
\begin{array}{r}
u r b_{i t}=\beta_{0}+\beta_{1} \mathrm{Sca}_{\mathrm{it}}+\delta_{i} X_{\mathrm{it}}+\mu_{\mathrm{i}}+\mathrm{v}_{\mathrm{t}}+\varepsilon_{\mathrm{it}}(3) \\
\operatorname{mar}_{i t}=\beta_{0}+\beta_{1} \mathrm{Sca}_{\mathrm{it}}+\delta_{i} X_{\mathrm{it}}+\mu_{\mathrm{i}}+\mathrm{v}_{\mathrm{t}}+\varepsilon_{\mathrm{it}}
\end{array}
$$

Among them, $i$ stands for the place, $t$ stands for the year, $L N Y$ stands for the effect of economic growth, Ind stands for the effect of industrialization, urb stands for the effect of urbanization, and mar stands for the effect of marketization. $S C A$ is the core explanatory variable, representing the size of the government, and $X$ is the control variable, including capital input rate, labor input

rate, economic openness and financial revenue ratio. $\mu_{\mathrm{i}}$ represents the individual specific effect that does not change with time, Represents a time effect that only changes with time represents a time effect that only changes with time, $c$ represents a random disturbance term independent of the explanatory variable.

\subsection{Index selection and variable definition}

- Explained variable. In this paper, the economic effect of government size is measured from four aspects: economic growth effect, industrialization effect, urbanization effect and market effect. Considering that the government's expenditure effect may have lag effect, referring to the research of some scholars such as Zhang Yan, Gong Liutang (2005), Zhang Gang and duanche (2006), the data of the four effects in the explanatory variables studied in this section represent the average value of the data of the current year and the total four years of the lag three years. The economic growth effect y is set as the logarithm of the real GDP; the industrial 
effect ind index selects the proportion of the total industrial output value in the real GDP; the urbanization effect $u r b$ index selects the proportion of the urban population in the total population; the market effect Mar measures the degree of the marketization by the proportion of the total non-state-owned industrial output value above the size of each region in the total industrial output value of the region.

- Core variables. SCA stands for the size of government. In this paper, the ratio of total fiscal expenditure to GDP is used as a measure of the size of government.

- Control variable. Capital input rate is the ratio of fixed asset investment to output. The amount of fixed assets investment is the workload of construction and purchase of fixed assets, which is expressed by currency. It is a comprehensive index reflecting the size, speed, proportion relationship and direction of use of fixed assets investment. Labor input rate, that is, the ratio of employment population to total population. The employment number of local population is not only affected by the economic structure and economic growth model, but also directly affects the economic development. Economic openness is measured by the ratio of total imports and exports to regional GDP. The ratio of fiscal revenue is measured by the proportion of the total fiscal revenue in the regional GDP to measure the regional economic burden.

\section{3 description of data}

This paper uses the data of Gansu Province, Qinghai Province, Ningxia Hui Autonomous Region and Xinjiang Uygur Autonomous Region from 2000 to 2015. All data are from China Statistical Yearbook, China Urban Statistical Yearbook, China Industrial statistical yearbook and development yearbooks of Northwest China. Table 1 is the definition and descriptive statistics of each variable index.

It can be seen from table 1 that the gap between the explained variables and the explained variables, namely, economic growth, industrialization, urbanization, marketization and the maximum and minimum value of government size, is relatively small, and the data is relatively flat. There is a large gap in the data of control variables, especially in the ratio of labor input and the degree of opening to the outside world. Due to the large differences in the population of each place in the four northwest provinces, the labor input rate is naturally different. Influenced by customs and policies, the strength of opening to the outside world is different, and the amount of import and export transactions open to the outside world is quite different.

TABLE I. DESCRIPTIVE STATISTICS OF PROVINCIAL DATA

\begin{tabular}{|c|c|c|c|c|c|c|}
\hline variables & & symbol & numbers & $\begin{array}{l}\text { mean } \\
\text { value }\end{array}$ & minimum & maximum \\
\hline \multirow[t]{4}{*}{$\begin{array}{l}\text { explained } \\
\text { variable }\end{array}$} & $\begin{array}{l}\text { economic } \\
\text { growth }\end{array}$ & Lny & 64 & 7.43875 & 5.574 & 9.14 \\
\hline & industrialization & Ind & 64 & 1.00675 & 0.574 & 1.452 \\
\hline & urbanization & $U r b$ & 64 & 33.07 & 12.19 & 62.48 \\
\hline & marketization & Mar & 64 & 1 & 0.999 & 1 \\
\hline \multirow{5}{*}{$\begin{array}{l}\text { explanatory } \\
\text { variable } \\
\text { control } \\
\text { variable }\end{array}$} & $\begin{array}{l}\text { government } \\
\text { size }\end{array}$ & Sca & 64 & 0.3225 & 0.14 & 0.627 \\
\hline & $\begin{array}{l}\text { capital input } \\
\text { rate }\end{array}$ & $k$ & 64 & 0.7325 & 0.4 & 1.33 \\
\hline & labor input rate & $L a b$ & 64 & 6.0365 & 0.03 & 20.24 \\
\hline & $\begin{array}{l}\text { economic } \\
\text { openness }\end{array}$ & Open & 64 & 0.08565 & 0.06 & 0.14 \\
\hline & $\begin{array}{l}\text { financial } \\
\text { revenue ratio }\end{array}$ & $\operatorname{Inc}$ & 64 & 0.484 & 0.36 & 0.59 \\
\hline
\end{tabular}



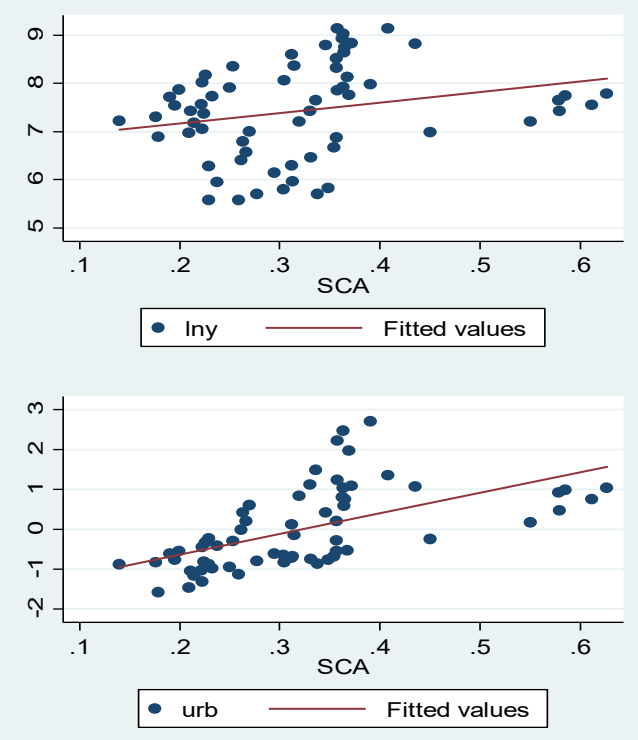
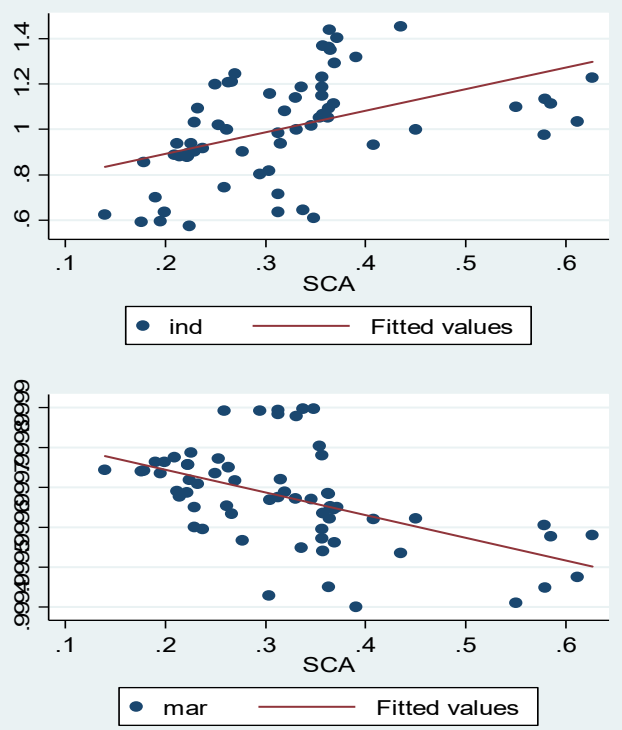

Figure 1. Scatter diagram of economic effect of government size

Figure 1 is a scatter fit. It can be seen that government size has a positive impact on economic growth; government size has a positive impact on industrialization; government size has a positive impact on urbanization; government size has a negative impact on marketization.

\section{Empirical results and econometric analysis}

In this paper, the panel data of four provinces in Northwest China from 2000 to 2015 are used for analysis. Through Hausman test, the p-value of four models is less than 0.01. Therefore, the fixed effect model is used in this paper. Since the data in this paper has been analyzed with data lagging for three years and four years in total, the dynamic model is no longer used for calculation.

Table 2 is the empirical analysis results of the economic effect of the provincial government size. The model (1) is the growth effect of the government size, the model (2) is the industrialization effect of the government size, the model (3) is the urbanization effect of the government size, the model (4) is the market effect of the government size, and the four models all adopt the fixed effect model.

TABLE II. EMPIRICAL RESULTS OF ECONOMIC EFFECTS OF PROVINCIAL GOVERNMENT SIZE

\begin{tabular}{lllll}
\hline variables & $(1)$ & $(2)$ & $(3)$ & $(4)$ \\
& \multicolumn{1}{c}{$\mathrm{FE}$} & $\mathrm{FE}$ & $\mathrm{FE}$ & $\mathrm{FE}$ \\
\hline sca & $3.488^{* * *}$ & $4.853^{* * *}$ & $1.276^{* * *}$ & $-0.0670^{*}$ \\
& $(0.932)$ & $(1.209)$ & $(0.491)$ & $(0.0352)$ \\
$k$ & $-0.973^{* *}$ & 0.915 & $1.209^{* * *}$ & $-0.0303^{* *}$ \\
& $(0.447)$ & $(0.580)$ & $(0.315)$ & $(0.0138)$ \\
open & $-0.0486^{* * *}$ & $-0.0427^{* *}$ & -0.0154 & -0.000555 \\
& $(0.0164)$ & $(0.0212)$ & $(0.0138)$ & $(0.000450)$ \\
inc & $12.30^{* *}$ & 5.452 & $11.98^{* * *}$ & 0.0382 \\
& $(4.819)$ & $(6.251)$ & $(2.530)$ & $(0.153)$ \\
lab & $8.980^{* * *}$ & 2.410 & 0.904 & 0.0276 \\
& $(2.416)$ & $(3.135)$ & $(1.476)$ & $(0.0654)$ \\
cons & $2.125^{*}$ & $-3.611^{* *}$ & $-3.038^{* * *}$ & $0.725^{* * *}$ \\
$N$ & $(1.089)$ & $(1.413)$ & $(0.759)$ & $(0.0342)$ \\
$R^{2}$ & 64 & 64 & 64 & 64 \\
\hline
\end{tabular}

a. where * represents the significance level of $0.1, *$ represents the significance level of $0.05, * * *$ represents the significance level of 0.01 


\subsection{Economic growth effect of government size}

From the model (1) in Table 2, the government size has a significant positive impact on economic growth, which shows that for the northwest minority areas, the proportion of government expenditure invested in local economic construction is higher, and the government expenditure effectively promotes the economic development of the northwest minority areas. The capital investment rate has a significant negative relationship with the local economic growth, which shows that the larger the fixed asset investment is, the less conducive to the local economic growth. The ratio of fiscal revenue has a significant positive impact on economic growth, which also shows that the increase of fiscal revenue provides a huge financial basis for government expenditure. With the increase of government revenue, a large part of government expenditure will be invested in local economic construction. The degree of economic openness has a significant negative relationship with the local economic growth, which shows that in the process of opening up to the outside world, the technology and products in the northwest minority areas lack international competitiveness and do not enjoy the dividends brought by opening up. Labor input rate has a significant positive impact on economic growth, which shows that the northwest minority areas are more laborintensive enterprises, labor as a basic factor of production, effectively promote economic growth, the same as most scholars' conclusions.

\subsection{Industrialization effect of government size}

The influence coefficient of government size on industrialization is positive and significant at $1 \%$ statistical level, indicating that government size can significantly improve the level of industrialization. The main reason is that part of the government expenditure flows to industry reasonably and effectively promotes the development of industrialization.

\subsection{Urbanization effect of government size}

The influence coefficient of government size on urbanization is positive and significant at $1 \%$ statistical level, which shows that government size can significantly promote the level of urbanization. Specifically, the urbanization level will be increased by 1.276 units for each unit of government expansion.

\subsection{Market effect of government size}

The size of government has a significant negative impact on marketization, which shows that the larger the size of government, the lower the degree of marketization, the larger the size of government and the greater the control over the market, it is extremely easy to form a stateowned monopoly industry, so that the market competitiveness is not enough and the degree of marketization is reduced.

\section{Conclusion}

The government should re understand the multiple effects of government size on economic and social development, especially the differences between the optimal size and the appropriate size.

The size of government can significantly promote the level of industrialization. This not only means that there is a lot of room for development in promoting the level of industrialization by increasing the size of the government, but also means that improving the size of the government can make the relevant industrialization policies smoothly implemented.

The process of urbanization in the four provinces of Northwest China is relatively slow. The expansion of government size is conducive to the development of urbanization in the four northwest provinces

Although China's market-oriented reform has made remarkable achievements, there are still many problems for the four northwest provinces. For example, the degree of marketization is not enough or the development of marketization is unbalanced.

\section{References}

1. Wen Yanbing. Expansion bias and welfare effect of government size [J]. China's Industrial Economy.2014(05):31-43.

2. Feng Haibo, Fang Yuanzi. Environmental effect analysis of local fiscal expenditure $[\mathrm{J}]$. Finance and Trade Economy.2014(02):30-43.

3. Fan Gang, Wang Xiaolu, Ma Guangrong. Contribution of China's marketization process to economic growth [J]. Economic Research. 2011(9): 4-16. 